\title{
B-Type Natriuretic Peptide and Troponin I as Possible Predictive Biomarkers for Cardiotoxicity Induced By Tricyclic Antidepressants and Antipsychotics Overdose
}

\author{
Aya Sabry Mohamed, Hoda M Salah Eldin and Manal Elsayed Abdel Salam ${ }^{1}$ \\ ${ }^{1}$ Department of Forensic Medicine \& Clinical Toxicology, Faculty of Medicine, Ain Shams University, Cairo, Egypt.
}

\begin{abstract}
Overdose by tricyclic antidepressants and antipsychotic drugs can lead to potentially lifethreatening cardiotoxicity. In clinical medicine, B-type natriuretic peptide (BNP) and cardiac troponin I (cTnI) are used as serum biomarkers in the diagnosis of cardiac affection.

Aim: The study aimed to investigate the utility of BNP and troponin I as early predictors for TCA and antipsychotic drug -induced cardiotoxicity and correlation with severity of poisoning.

Method: The study enrolled 45 patients admitted in ICU of Poison Control Center of Ain Shams University Hospitals (PCC-ASUH) with history of tricyclic antidepressants (TCA) and /or antipsychotics overdose. Collected data included sociodemographic data, manner of exposure, clinical variables, ECG changes, Poison Severity Score (PSS), serum levels of BNP and cTnI. Duration of ICU and hospital stay, and outcome were also noted.

Results: In contrast to CTnI level, BNP level was significantly higher in cardiotoxicity group. Mean BNP level correlated with ECG and blood pressure changes. Biomarkers levels were nonsignificantly correlated with PSS, total hospital stay \&ICU stay. PSS had low sensitivity and accuracy for prediction of cardiotoxicity. Both BNP and cTnI showed at specific cut off point showed $100 \%$ specificity with sensitivity of $53.13 \%$ \& $25.0 \%$ respectively

Conclusion: Although unsuitable for screening purposes, BNP surpassed cTnI as a useful tool for the diagnosis of cardiotoxicity due to overdose by tricyclic antidepressants and antipsychotic drugs

Key words $\quad$ B-type natriuretic peptide - Troponin I - biomarkers - cardiotoxicity -tricyclic antidepressants antipsychotics -overdose
\end{abstract}

\section{Introduction}

A ccidental and intentional drug overdoses constitute a significant cause of morbidity, mortality, and increased health care cost worldwide. Although trends vary according to geographical region, psychiatric agents are among the most commonly encountered drugs in poisoning cases. Clinical effects of tricyclic antidepressants and antipsychotic drugs overdose can lead to potentially life-threatening neurological and cardiac complications (Borg et al., 2016).

Both tricyclic antidepressants and antipsychotic drugs can significantly induce distinct cardiotoxicity through multiple and sometimes divergent effects on the cardiovascular system; both are known to increase the risk of potentially lifethreatening arrhythmias and sudden cardiac death (SCD). These proarrhythmic effects have been linked to prolongation of QT interval of the electrocardiogram (ECG). Studies have also shown that TCAs directly decrease myocardial contractility in a dose dependent manner and cause peripheral vasodilatation by antagonism of peripheral alpha-1 adrenergic receptors resulting in refractory hypotension (Pierog et al., 2009;
Tarek et al.,2016; Sabah et al., 2017).Antipsychotics were additionally implicated in other cardiac complications including myocarditis, cardiomyopathy and left ventricular dysfunction with sometimes fatal effect (Curto et al.,2015).

In clinical practice, numerous serum biomarkers are proposed for diagnosis of drug-induced cardiotoxicity. Previous studies point that troponin I can be used as a potent biomarker of toxic cardiac injury when irreversible myocyte injuries with loss of sarcolemmal integrity are present regardless of the cardiotoxic agents involved (Sorodoc et al., 2013).Btype natriuretic peptide (BNP) and N-terminal fragment of its prohormone (NT-proBNP) are cardiacderived polypeptides predominately secreted from ventricular myocardium in response to volume and pressure overload. Both can be viewed as quantitative markers of ventricular dysfunction and well-established predictors of disease state in symptomatic and asymptomatic patients with suspected heart failure(Mueller et al., 2007; Khalaf et al., 2011;Sorodoc et al., 2013; Zoltani, 2014). 
As cardiotoxicity was suggested as a significant determinant of morbidity and mortality in both therapeutic and overdose cases, assays for clinical detection of cardiotoxicity can be employed in risk stratification, management and clinical prediction of morbidity /mortality.

\section{Aim of work}

The study aimed to investigate the role of BNP and troponin I as early predictors for TCA and antipsychotic drug -induced cardiotoxicity and correlation with severity of poisoning.

\section{Patients and method Design and setting}

A cross-sectional hospital-based observational study was carried out on 45 patients of both genders admitted in ICU of Poison Control Center of Ain Shams University Hospitals (PCC-ASUH) with history of tricyclic antidepressants (TCA) and /or antipsychotics overdose.

\section{Ethical Considerations}

The study was approved by the Research Ethics Committee of Faculty of Medicine Ain Shams University. All collected data were stored anonymously with consideration of confidentiality issues and used only for the purpose of the study and were considered.

\section{Participant selection and grouping}

Patients exposed to tricyclic antidepressants and /or antipsychotics ingestion within $6 \mathrm{~h}$ and admitted in ICU were selected. The diagnosis of intoxication was based on history and clinical examination.

Diagnosis of cardiotoxicity was determined by the presence of one or more of the clinical manifestations that include hemodynamic instability, heart failure, cardiac conduction abnormalities and dysrhythmias; and/or ECG manifestations. Patients were divided into two major groups:

- First group (Exposure without cardiotoxicity): patients exposed to one of the selected cardiotoxic agents, but without detectable cardiotoxicity.

\section{- Second group (Exposure with overt cardiotoxicity)}

Based on the possibility of alteration in measured parameters and/or biomarkers exclusion criteria included ages above 60 years and history of cardiovascular or medical disease.

\section{Parameters}

Sociodemographic data (age, gender, residence) and manner of exposure were recorded at enrollment. This is in addition to recording duration of admission in the ICU, total period of hospitalization and outcome (including complete recovery, or fatality).

Examination of the patients was carried out at the time of presentation to the PCC and periodically for follow up. Clinical data included pulse, mean blood pressure, respiratory rate and temperature. Normal values were stated according to McGrath \& Bachmann (2018). CNS manifestations included evaluation of conscious level according to Reed's classification (Karmakar, 2015) ,seizures and agitation. Electrocardiography was performed at the time of admission in addition to continuous cardiac monitoring.
Investigations and treatment were performed according to specific requirements of each patient following the guidelines of the PCC protocols. General laboratory investigations (done routinely in the ICU) included random blood sugar, serum sodium and potassium, serum urea and creatinine, serum ALT and AST and arterial blood gases. Serum biomarkers namely BNP and cTnI were measured on admission.

BNP: measurement was done using the Human Brain Natriuretic Peptide Enzyme Linked Immunosorbent Assay (ELISA)Kit of Bioassay Technology Laboratory., Shanghai, China.

Cardiac TnI: measurement was done by using Enzyme Immunoassay test kit for the Quantitative determination of cardiac troponin-I in human serum.

All clinical and laboratory variables were recorded and employed in the calculation of poison severity score (PSS) which is a classification scheme for cases of acute poisoning in adults and children. Based on the overall clinical course, PSS was applied according to the most severe symptomatology (including both subjective symptoms and objective signs). The severity was graded from 0 to 4 , ranging from absent toxicity to death (Persson et al.,1998).

\section{Results}

By the end of the study, antipsychotics overdosed cases outnumbered those overdosed by TCA: constituting $75.56 \%$ of total number of cases. In relation to the occurrence of overt cardiotoxicity, group II included 32 cases $\mathbf{( 7 1 . 1 1 \% )}$ with statistically non-significant difference in relation to the type of drug (Table 1).

Mean age among overall patients in the study was $24.511 \pm 9.715$ years with a statistically significant higher mean in cases with overt cardiotoxicity (26.500 \pm 10.100 yrs.) versus (19.615 \pm 7.343 yrs.) in those without detectable cardiotoxicity (Table 2).

As regard gender and residence, patients enrolled in this study were mostly females (68.89\%) and from urban areas (84.44\%). The manner of exposure was mostly suicidal (93.33\% of cases). No statistically significant difference was found between group I and group II as regard gender, residence\& manner of exposure (Table 3).

Although, tachycardia was observed in $73.33 \%$ of cases mostly among overt cardiotoxicity group, there was no significant difference between the two groups as regard pulse. Regarding ECG findings, all patients had regular rhythm, with normal PR interval. Prolonged QTC interval was observed in $35.56 \%$ of cases, and in association with wide QRS complex in $13.33 \%$ all among group II. Hypertension was observed in $33.33 \%$ of cases, while hypotension was only observed in a minority (8.89\%) all among cardiotoxicity group. Prolonged QTC and/or wide QRS and blood pressure changes showed significant differences between the two groups. While hyperthermia was observed in $13.33 \%$, tachypnea was observed in $53.33 \%$ of cases mostly among group II, however with no statistical significance in relation to cardiotoxicity (Table 4).

Coma grade II was recorded in nearly half of the cases $(51.11 \%)$ followed by coma grade I in $42.22 \%$, while coma grade III and IV were only 
recorded in a minority of cases. Seizures and agitation were recorded in $12.50 \%$ and $26.67 \%$ of patients respectively. The majority of cases recovered completely on discharge (93.33\%). Fatality was only recorded in 3 cases. Neither neurological manifestations nor outcome had significant difference between group I and II as (Table 4).

Calculated PSS for cases ranged from 2-4 with no significant difference between the two groups. The mean length of stay in ICU and total hospital stay were longer in group II compared to that of group I, however it was not statistically significant (Table 5).

Mean serum levels of cTnI levels ranged from 0.01-1 ng/ml while those of BNP ranged from 250-600 $\mathrm{pg} / \mathrm{ml}$. Both biomarkers had higher mean values among overt cardiotoxicity group compared to group I, however this difference had statistical significance only for BNP (Table6).
The mean values of cTnI showed no statistically significant difference in relation to pulse, blood pressure and ECG finding in addition to PSS, length of ICU and total hospital stay. In contrast to TnI, BNP levels showed statistically significant difference in group II as regards blood pressure changes and $\mathrm{QT}_{\mathrm{C}}$ interval (Table 7, Figure1).

Test characteristics of cTnI for diagnosis of cardiotoxicity were $25 \%$ sensitivity, $100 \%$ specificity, $35.1 \%$ negative predictive value and $62.5 \%$ accuracy. The optimal TnI cut-off points along the ROC curve were at values $>0.02 \mathrm{ng} / \mathrm{mL}$. At cut-off levels $>320$ $\mathrm{pg} / \mathrm{mL}$, BNP was higher in sensitivity (53.13 \%) and accuracy (80.4\%) over cTnI with equal specificity $(100 \%)$ in diagnosis of cardiotoxicity (Table8, Figure2). PSS at cut off point $>2$ was $37.50 \%$ sensitive, $76.92 \%$ specific with accuracy of $56.5 \%$ for prediction of cardiotoxicity (Table8, Figure3).

Table (1): Chi-Square statistical analysis showing comparison between group I and II as regards distribution of the type of drug

\begin{tabular}{|c|c|c|c|c|c|c|c|c|}
\hline \multirow{3}{*}{ Drug } & \multicolumn{6}{|c|}{ Groups } & \multirow{2}{*}{\multicolumn{2}{|c|}{ Chi-Square }} \\
\hline & \multicolumn{2}{|c|}{ Group I } & \multicolumn{2}{|c|}{ Group II } & \multicolumn{2}{|c|}{ Overall cases } & & \\
\hline & $\mathbf{N}$ & $\%$ & $\mathbf{N}$ & $\%$ & $\mathbf{N}$ & $\%$ & $\mathrm{X} 2$ & P-value \\
\hline TCA & 4 & 30.77 & 7 & 21.88 & 11 & 24.44 & \multirow{3}{*}{0.396} & \multirow{3}{*}{0.529} \\
\hline Antipsychotics & 9 & 69.23 & 25 & 78.13 & 34 & 75.56 & & \\
\hline Overall cases & 13 & 100.00 & 32 & 100.00 & 45 & 100.00 & & \\
\hline
\end{tabular}

$N$ : number of cases $p>0.05=$ statistically non-significant, $p<0.05=$ statistically significant

Table (2): Student's $t$-test statistical analysis showing comparison between group I and II as regards age

\begin{tabular}{|l|ll|ll|l|l|}
\hline \multirow{2}{*}{ Age } & Groups & \multicolumn{4}{|l|}{ T-Test } \\
\cline { 2 - 7 } & Group I & Group II & t & P-value \\
\hline Range & 8 & -30 & 15 & - & \multirow{2}{*}{-2.224} & $0.031^{*}$ \\
\hline Mean \pm SD & 19.615 & \pm 7.343 & 26.500 & \pm 10.100 & & \\
\hline
\end{tabular}

SD: standard deviation, $p>0.05=$ statistically non-significant, ${ }^{*} p<0.05=$ statistically significant

Table (3): Chi-Square statistical analysis showing comparison between group I and II as regards gender, residence \& manner of exposure

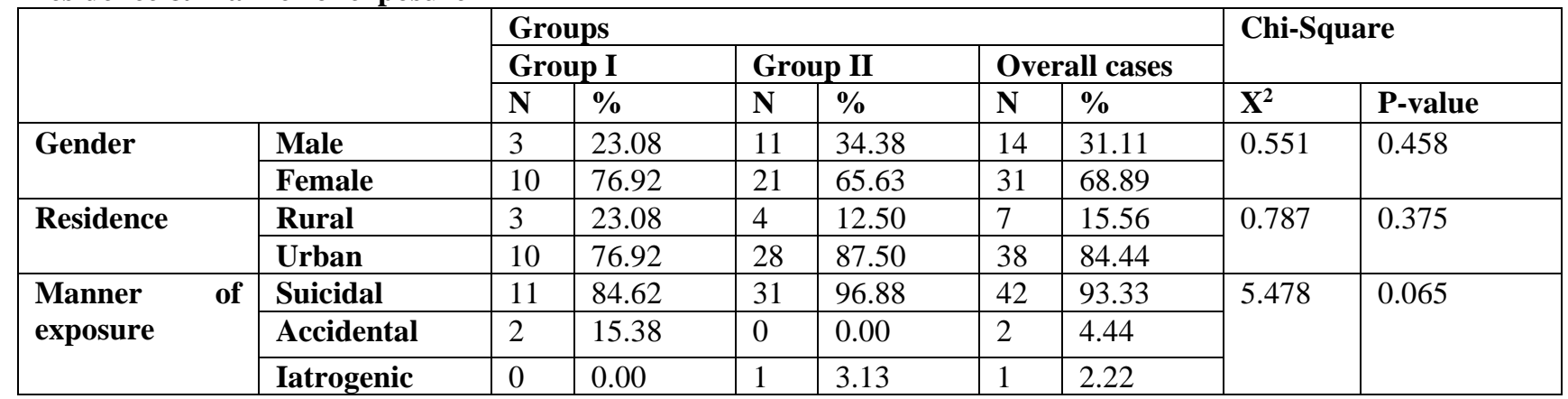

$N$ : number of cases, $p>0.05=$ statistically non-significant, $p<0.05=$ statistically significant 
Table (4): Chi-Square statistical analysis showing comparison between group I and II as regards clinical variables and outcome

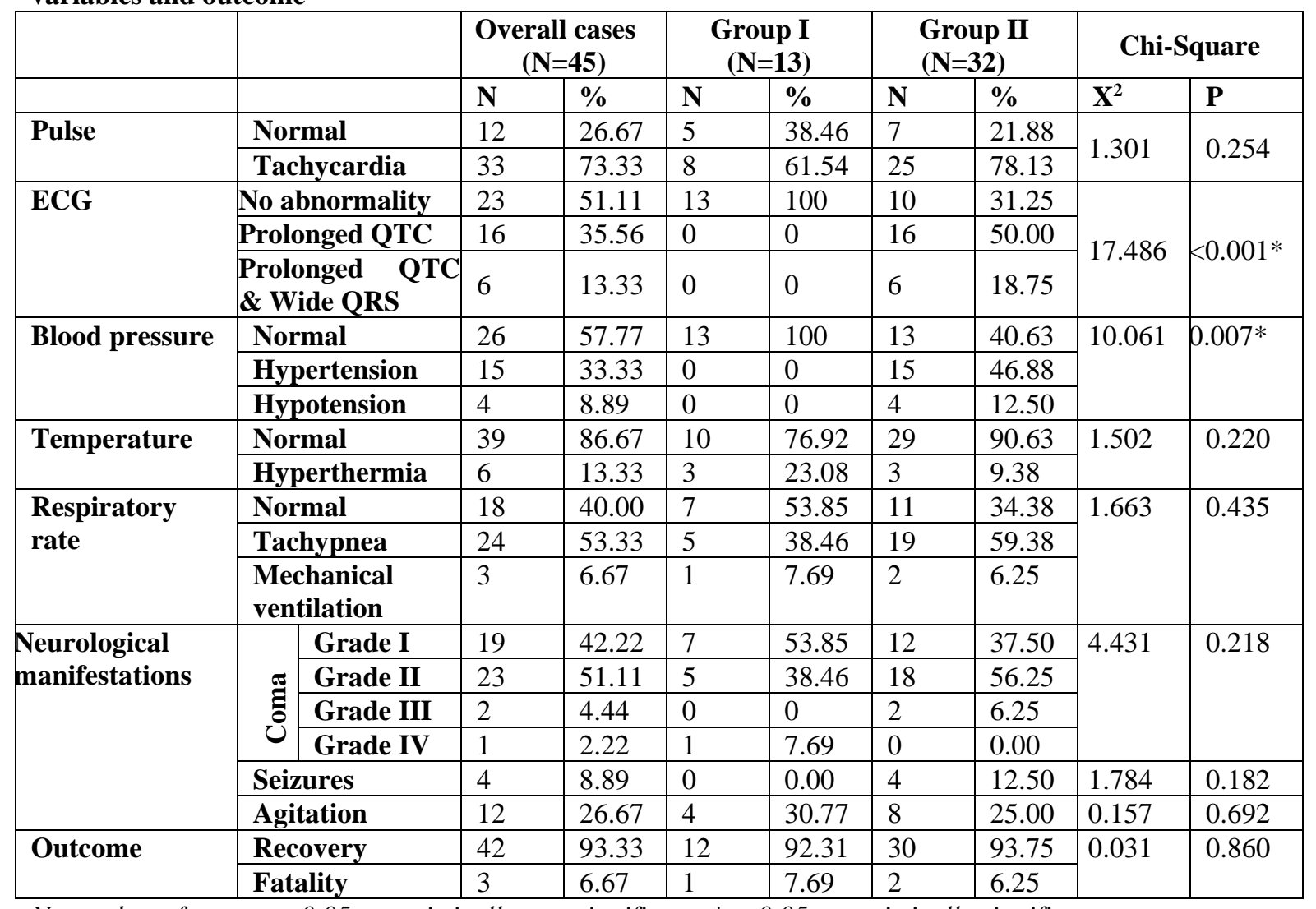

$N$ : number of cases, $p>0.05=$ statistically non-significant, ${ }^{*} p<0.05=$ statistically significant

Table (5): Student's t-test statistical analysis showing comparison between group I and II as regards PSS, duration of hospital stay, and ICU stay

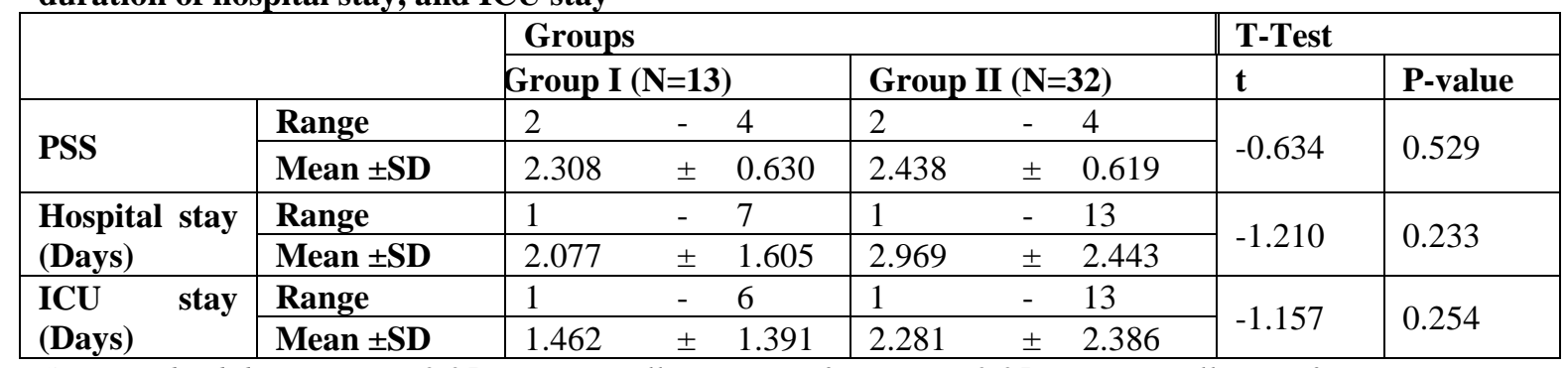

SD: standard deviation, $p>0.05=$ statistically non-significant, ${ }^{*} p<0.05=$ statistically significant

Table (6): Student's t-test statistical analysis showing comparison between group I and II as regards investigated cardiac biomarkers.

\begin{tabular}{|c|c|c|c|c|c|c|c|c|c|}
\hline \multicolumn{8}{|c|}{ Groups } & \multicolumn{2}{|l|}{ T-Test } \\
\hline & & Group I( & & & Group I & $\mathbf{N}=$ & & $\mathbf{t}$ & P-value \\
\hline \multirow{2}{*}{ cTnI (ng/ml) } & Range & 0.01 & - & 0.2 & 0.01 & - & 1 & \multirow{2}{*}{-1.567} & \multirow{2}{*}{0.124} \\
\hline & Mean \pm SD & 0.046 & \pm & 0.073 & 0.162 & \pm & 0.260 & & \\
\hline \multirow{2}{*}{ BNP (pg/mL) } & Range & 180 & - & 320 & 250 & - & 600 & \multirow{2}{*}{-3.651} & \multirow{2}{*}{$0.001^{*}$} \\
\hline & Mean \pm SD & 261.538 & \pm & 50.801 & 355.313 & \pm & 86.360 & & \\
\hline
\end{tabular}

SD: standard deviation, $p>0.05=$ statistically non-significant, ${ }^{*} p<0.05=$ statistically significant 
Table(7): Correlations between investigated cardiac biomarkers and selected parameters.

\begin{tabular}{|l|l|l|l|l|}
\hline Correlations & \multicolumn{5}{l|}{ BNP (pg/mL) } & \multicolumn{2}{l|}{ Troponin I (ng/ml) } \\
\cline { 2 - 5 } & $\mathbf{R}$ & P-value & R & P-value \\
\hline PSS & 0.163 & 0.284 & 0.082 & 0.593 \\
\hline Hospital stay (Days) & 0.030 & 0.842 & -0.027 & 0.860 \\
\hline ICU stay (Days) & 0.068 & 0.656 & 0.033 & 0.828 \\
\hline PR & 0.105 & 0.494 & -0.146 & 0.338 \\
\hline QRS & 0.182 & 0.231 & 0.156 & 0.307 \\
\hline QTC & 0.339 & $0.023^{*}$ & -0.032 & 0.834 \\
\hline
\end{tabular}

${ }^{*} p<0.05$ = statistically significant, $r=$ Pearson correlation coefficient.

Table (8): Sensitivity and specificity of investigated cardiac biomarkers and PSS in diagnosis of cardiotoxicity ROC curve between Group I and Group II

\begin{tabular}{|c|c|c|c|c|c|c|}
\hline & Cutoff & Sensitivity & Specificity & PPV & NPV & Accuracy \\
\hline BNP (pg/mL) & $>320$ & 53.13 & 100.0 & 100.0 & 46.4 & $80.4 \%$ \\
\hline cTnI (ng/ml) & $>0.2$ & 25.0 & 100.0 & 100.0 & 35.1 & $62.5 \%$ \\
\hline PSS & $>2$ & 37.50 & 76.92 & 80.0 & 33.3 & $56.5 \%$ \\
\hline
\end{tabular}

PPV: positive predictive value, NPV: negative predictive value.

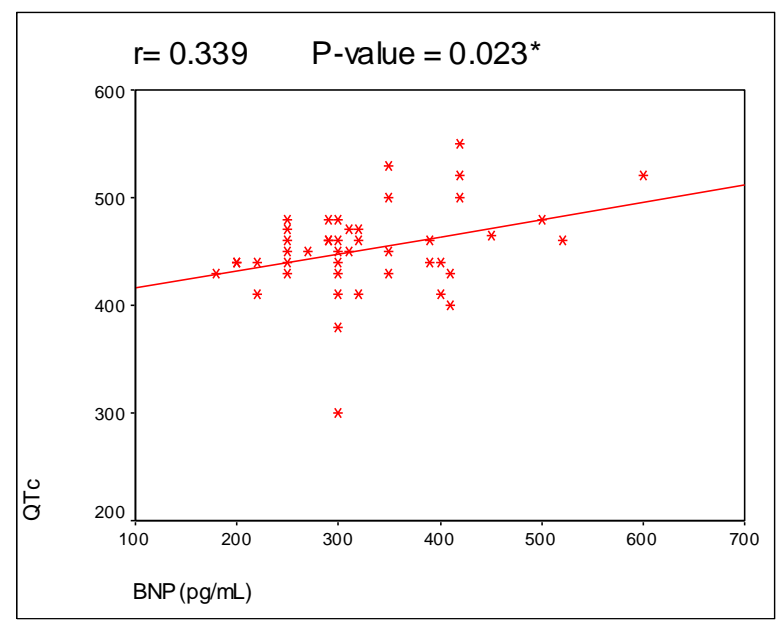

Figure (1): Correlation between BNP and QTc
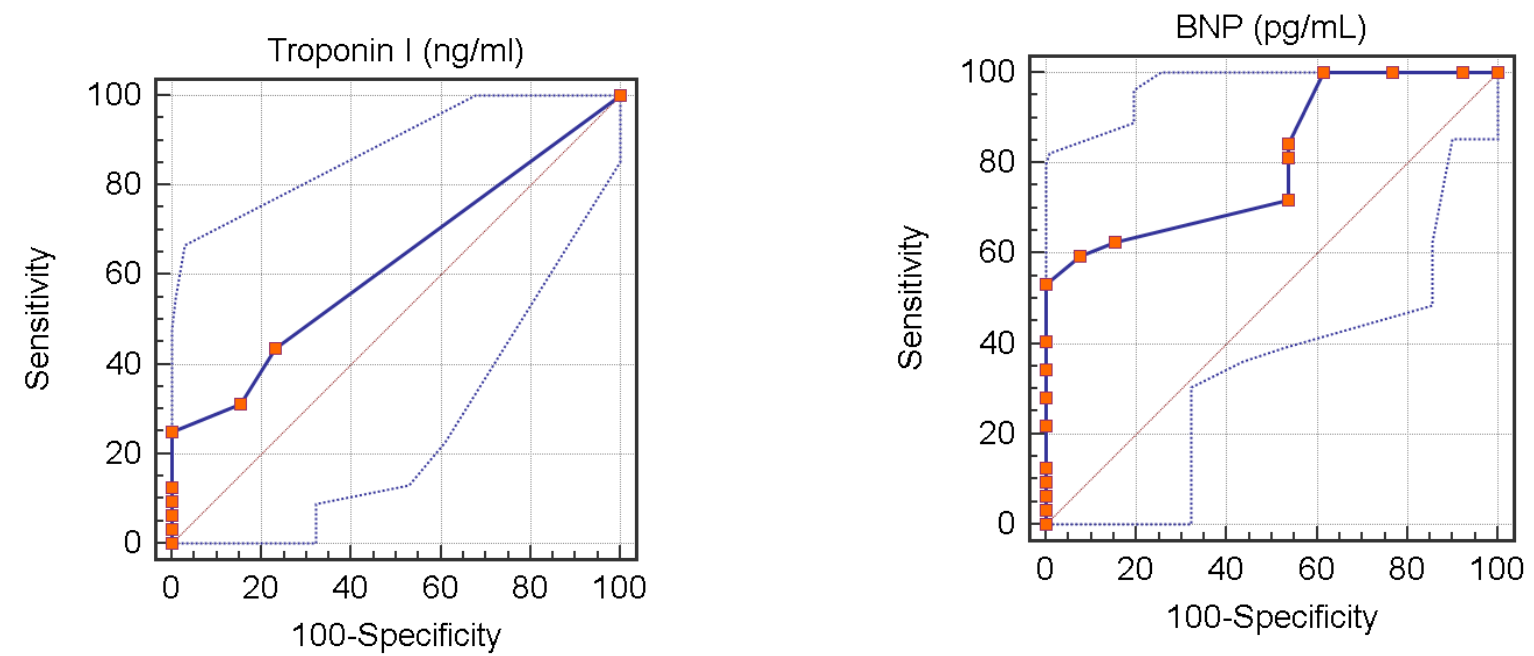

Figure (2): Receiver Operating Characteristic (ROC) curves of cTnI and BNP for the diagnosis of cardiotoxicity. 


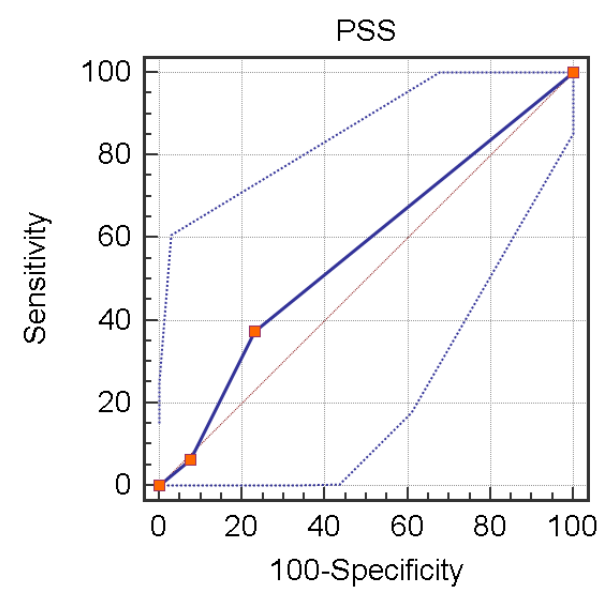

Figure (3): ROC curves of PSS for the diagnosis of cardiotoxicity.

\section{Discussion}

Mean age among overall patients in the study was $24.511 \pm 9.715$ years with a statistically significant higher mean in cases with overt cardiotoxicity although patients over 60 years old were excluded. Several studies have identified increased age as an important cardiotoxic risk factor (Naumann et al., 2013; Perez et al., 2008;Tan-Chiu et al.,2005).

On the contrary, a study performed by Jones et al.(2013) to assess risk of cardiac events and mortality among users of some antipsychotics relative to nonusers, increased risk of both cardiac mortality and all-cause mortality was observed in younger versus older patients.

Aging is associated with a progressive decline in numerous physiological processes, leading to an increased risk of health complications and disease. Both the heart and vasculature undergo numerous alterations during aging including hypertrophy, altered left ventricular (LV) diastolic function, increased arterial stiffness, and impaired endothelial function. At the molecular level, as endothelial cells age, they exhibit a reduction in endothelial nitric oxide synthetase activity. At the cell level, cardiomyocytes become more susceptible to stress, including oxidative stress leading to decrease in absolute number of cardiomyocytes as a result of increased apoptosis and necrosis and a decrease in repopulation of cardiomyocytes from cardiac stem cell reserves (North \& Sinclair, 2012).

The female predominance among patients in the present study can be viewed in relation to the prevalence of deliberate self-poisoning as the main manner of intoxication and urban living as the main residence. Studies demonstrated that females tend to prefer auto-aggressive behaviors as intentional poisoning compared to violent methods in suicide attempts. In the same way, increased suicide risk among women was also linked to urban residence (Qin,2005; Kaess et al. ,2011; Foto-Ozdemir et al. ,2016) .

No statistically significant gender difference in the occurrence of overt cardiotoxicity was observed in the current study. This is on the contrary to studies suggesting a biological difference in sensitivity of women to drug- induced cardiac arrhythmias owing to longer QT interval from the age of puberty to old age. However, detailed actions of gender hormones and their role in the gender differences in QTc is not clearly defined and requires further research (Kannankeril et al.,2010; Rabkin,2016).

In the current study sinus tachycardia was observed in $73.33 \%$ of cases. This was not unexpected as sinus tachycardia was reported as the most common arrhythmia with TCAs overdose and was attributed to anticholinergic activity and/or inhibition of norepinephrine uptake by TCAs. Similarly antipsychotics cause tachycardia as a vasomotor reflex to hypotension or due to anticholinergic effects. (Thanacoody \& Thomas , 2005; Juurlink 2015).

As regard blood pressure, normal blood pressure was observed in a more than half of cases, however blood pressure changes either as hypertension or hypotension showed statistical difference in cardiotoxicity group.

TCA $_{\mathrm{s}}$ and antipsychotic drugs have multiple effects on the cardiovascular system. Early hypertension is common with overdose as a result of their anticholinergic effect and excess norepinephrine in the synapse from blockade of norepinephrine reuptake. On the other hand, hypotension occurs mainly as a result of alpha-receptor antagonism, norepinephrine depletion. Hypotension may also reflect decreased myocardial contractility due to sodium channel antagonism by TCAs especially in overdose cases (Khasawneh \& Shankar, 2014;Levine \& Ruha, 2012).

In the present study, tachypnea was observed in $53.33 \%$ of patients, while hyperthermia was observed in $13.33 \%$. The present study showed no significant difference regarding temperature and respiratory rate in relation to occurrence of cardiotoxicity. Hyperventilation may be attributed to arterial hypoxemia or tissue hypoxia which stimulates peripheral chemoreflex. Also, it may be a response to hyperthermia or anxiety. On the other hand, anticholinergic effects of TCA and antipsychotics, especially in the presence of seizures or agitation may account for the associated hyperthermia ((Juurlink, 2015; Greenbaum, 2016). 
In the present study, regarding ECG findings, statistically significant difference between the two groups was found as prolonged QTc and/or wide QRS were observed in almost half of the cases (48.89\%) all among overt cardiotoxicity group.

Liebelt(2008) pointed to the occurrence of ECG changes both in the setting of therapeutic and toxic doses of Antipsychotics and TCAs. Several studies reported QTC prolongation and wide QRS complex were common findings in patients with TCAs or antipsychotics overdose (Açikalin et al., 2010; Khalaf et al., 2011; Saleh et al.,2013 ; Karakiliç et al. ,2016; Mishra \&Kumar,2018)

The potential mechanism underlying QT prolongation by antipsychotic drugs is based on their ability to block the rapidly activating delayed rectifier potassium current $\left(\mathrm{I}_{\mathrm{Kr}}\right)$, which leads to lengthening of cardiac repolarization Regarding TCAs, they inhibit sodium channel conductance, so that phase 0 cardiac depolarization is delayed. This may cause slower conduction within the His-Purkinje fibers and ventricular myocardium, causing prolongation of the QRS complex on the ECG (Leung et al., 2012; Waring, 2012).

In the current study, neurological manifestations (either in the form of coma, seizures or agitation) showed no significant difference between group I and II. TCAs and antipsychotics induced altered mental status, agitation and seizures could be attributed to their antimuscarinic and antihistaminic action, diminished cerebral perfusion secondary to hypotension and $\gamma$-amino butyric acid antagonism (Levine et al., 2012;Ruha \& Levine, 2014).

In the present study, calculated PSS for cases showed no significant difference between the two groups. Moreover, PSS at cut off point $>2$ was $37.50 \%$ sensitive, $76.92 \%$ specific with accuracy of $56.5 \%$ for prediction of cardiotoxicity.

These results can be interpreted in view of studies stating that PSS may not be the ideal score to be used for all global toxicological exposures. PSS has several subjective criteria, is time consuming to score, and is likely to be of little use with some types of poisonings, limiting its clinical utility. Also, being frequently modified or misapplied, makes it difficult to assess its accuracy or utility so (Schwarz et al. ,2017)

On the contrary, Zaaqoq et al. (2012) found that a PSS of 2 has a sensitivity of $88 \%$ and a specificity of $64.7 \%$ for prediction and early diagnosis of cardiotoxicity. Also, Churi et al. (2012) mentioned that PSS score demonstrated excellent sensitivity with clinical outcome, thereby indicating its usefulness to predict severity in emergency centers.

In the current study, although troponin I levels ranged from $0.01-1 \mathrm{ng} / \mathrm{ml}$ with higher mean among overt cardiotoxicity group compared to group I, however this difference had no statistical significance. Similarly, this study found no association between troponin I elevation as diagnostic marker of cardiotoxicity and clinical predictors of severity of acute drug overdose due to TCA and antipsychotics: the mean values of troponin I showed no statistically significant difference in relation to pulse, blood pressure and ECG finding in addition to PSS, length of ICU and total hospital stay.

However, the current study highlighted the diagnostic ability of troponin in detection of induced cardiotoxicity with $100 \%$ specificity, $35.1 \%$ negative predictive value and $62.5 \%$ accuracy at cut-off points at values $>0.02 \mathrm{ng} / \mathrm{mL}$.

Low sensitivity of troponin I in this setting may be interpreted on the grounds of the potential for false negatives: Cardiac troponin is controversial as a marker for cell injury which does not involve cell membrane disruption such as sublethal and cytocidal injuries and hence not associated with measurable increases in the serum. Sub-lethal injury may be present in rhythm changes, altered electrical activity, contractile dysfunction or reversible ischemic injury. Similarly, depending upon the extent of secondary necrosis, apoptotic myocardial injury in the setting of some types of cardiotoxicity may not lead to release of troponin into the serum within the diagnostic window (Wallace et al., 2004; Jaffe\& Wu, 2012).

On the contrary to the present work, a large body of research demonstrated the utility of cardiac troponins monitoring potential drug-induced myocardial injury following the administration of antineoplastic drugs in both clinical and preclinical studies (Adamcova et al., 2005; Gaz \& Collinson, 2005; Manini et al., 2016).

Despite the advantages of cardiac troponins of high specificity and sensitivity however a number of questions are still unanswered including the assessment of suitable cutoff for drug-induced cardiotoxicity and determination of critical diagnostic window related to the optimal timing of sample collection, which may be drug-dependent. Additionally, presence of troponin elevation implies that myocardial cell death has already occurred, hence raising questions about its role as an effective early marker of cardiotoxicity (Adamcova et al., 2005; Tan \& Lyon, 2018; Pointon A \& Edmunds,2019).

As regards BNP in the present study, mean serum levels ranged from 250-600 pg/ml with significantly higher mean among overt cardiotoxicity group compared to group I. It is worth noting that BNP levels in both group I and II were both above the threshold value of elevated BNP for cardiac dysfunction has been accepted to be $100 \mathrm{pg} / \mathrm{mL}$ in the literature.

In comparison with recorded troponin I mean values, the mean values of BNP showed no statistically significant difference in relation to some clinical parameters including pulse, PSS, length of ICU and total hospital stay but correlated significantly with blood pressure changes and ECG findings namely QTC interval.

Taken together, these results may reflect the potential of BNP to serve as a biomarker to indicate sub-clinical cardiac dysfunction in the context of acute cardiotoxicity due to acute overdose by TCA and antipsychotics.

The correlation between increased BNP levels and hypotension is in accordance with Dillinger et al. (2011) who noted that serial BNP measurements 
following cardiotoxic drug poisoning are useful to identify patients at the highest risk of cardiogenic shock and in hospital mortality. Karakiliç et al. (2016) similarly detected a significant correlation between measurement of blood BNP level and degree of cardiac involvement indicated by hypotension and ECG findings in patients with poisoning by drugs having cardiotoxic potential.

BNP is a clinical indicator of cardiac hemodynamic responses and dysfunction widely accepted for diagnosis of congestive heart failure, septic shock and myocardial infarction. Clinically relevant levels of BNP have been linked to severity of left ventricular failure and predicted cardiovascular events in asymptomatic cases. Studies have shown the potential to serve as a biomarker for sub-clinical cardiac dysfunction in the context of cardiotoxicity prior to any measurable changes in traditional echocardiography (Wang et al,2016; Pointon A \& Edmunds,2019).

In the present study, at cut-off levels $>320$ $\mathrm{pg} / \mathrm{mL}$ BNP was superior in sensitivity (53.13 \%) and higher diagnostic accuracy (80.4\%) over troponin I with equal specificity (100\%) in detection of induced cardiotoxicity. These data suggest that the use of BNP can increase the accuracy of clinical evaluation of cardiotoxicity.

\section{Conclusion}

TCA and antipsychotic drug overdose are related to occurrence of cardiac toxicity. Although PSS is an "athand" tool for evaluation of poisoning cases but it has a limited significance in this work owing to its low sensitivity and accuracy for diagnosis of cardiotoxicity and being uncorrelated to biomarkers levels. BNP level correlated with $\mathrm{QT}_{\mathrm{C}}$ interval and blood pressure changes and surpassed cTnI as a useful tool for the diagnosis of cardiotoxicity. However, both tested biomarkers are unsuitable for screening purposes.

\section{Recommendation}

Studies are needed to better characterize time-course of BNP changes in acute drug-induced cardiovascular disturbances by serial measurements of plasma levels. Moreover, combination of a cardiac biomarker approach with an ECG approach is strongly suggested and should be furtherly investigated for risk stratification of drug overdose patients and clinical prediction of acute drug-induced cardiotoxicity. As the field of prediction, detection, and management of cardiotoxicity is receiving much interest, future studies are needed to incorporate new biomarkers and their role in drug-induced cardiotoxicity.

\section{References}

Açikalin A, Satar S, Avc A et al., (2010): QTc intervals in drug poisoning patients with tricyclic antidepressants and selective serotonin reuptake inhibitors. American journal of therapeutics. 17(1):30-3.

Adamcova M, Šterba M, Šimunek T et al., (2005): Troponin as a marker of myocardiac damage in drug-induced cardiotoxicity. Expert opinion on drug safety. 4(3):457-72.
Borg L, Julkunen A, Rørbæk Madsen K et al., (2016): Antidepressant or antipsychotic overdose in the Intensive Care Unit-Identification of patients at risk. Basic \& clinical pharmacology \& toxicology. 119(1):110-4.

Churi S, Ramesh M, Bhakta K et al., (2012): Prospective assessment of patterns, severity and clinical outcome of Indian poisoning incidents. Chemical and Pharmaceutical Bulletin. 60(7):859-64.

Curto M, Comparelli A, Ciavarella GM et al., (2015): Impairment of left ventricular function early in treatment with clozapine: a preliminary study. International clinical psychopharmacology. 30(5):282-9.

Dillinger JG, Deye N, Logeart D, et al., (2011): Prognostic value of plasma B-type natriuretic peptide in patients with severe cardiotoxic drug poisoning. Acute cardiac care. 13(3):174-80.

Foto-Özdemir D, Akdemir D and Çuhadaroğlu-Çetin F (2016): Gender differences in defense mechanisms, ways of coping with stress and sense of identity in adolescent suicide attempts. Turkish Journal of Pediatrics. 58(3).

Gaze DC and Collinson PO (2005): Cardiac troponins as biomarkers of drug-and toxin-induced cardiac toxicity and cardioprotection. Expert opinion on drug metabolism \& toxicology. 1(4):715-25.

Greenbaum LA (2016): Fluid and Electrolyte Disorders. In: Nelson Textbook of Pediatrics, Kleigman RM, Stanton J, and Geme WS et al (eds), $20^{\text {th }}$ ed., Elsevier, Philadelphia USA, pp.346-384.

Jaffe AS and Wu AH (2012): Troponin releasereversible or irreversible injury? Should we care? Clinical chemistry. 58(1):148-50.

Jones ME, Campbell G, Patel D et al., (2013): Risk of mortality (including sudden cardiac death) and major cardiovascular events in users of olanzapine and other antipsychotics: A study with the general practice research database. Cardiovascular psychiatry and neurology. 2013.

Juurlink DN (2015): Antipsychotics. In: Goldfrank's Toxicologic Emergencies, Hoffman RS, Howland MA, Lewin NA, et al., (eds), $10^{\text {th }}$ ed., McGraw-Hill, NY, pp. 960-71.

Kaess M, Parzer P, Haffner J et al., (2011): Explaining gender differences in non-fatal suicidal behaviour among adolescents: a populationbased study. BMC Public Health. 11(1):597.

Kannankeril P, Roden DM and Darbar D (2010): Druginduced long QT syndrome. Pharmacological reviews. 62(4):760-81.

Karakiliç E, Solakoğlu G and Karakiliç ID (2016): Relationship Between BNP and Cardiovascular Toxicity Acta Medica Mediterranea, 32: 1791

Karmakar RN (2015): Forensic medicine and toxicology: theory, oral \& practical, $5^{\text {th }}$ ed. Academic Publishers, Kolkata, pp 59-141. 
Khalaf MA, AbdelRahman TM and Abbas MF (2011): Values of using QTc and N-terminal fragment of B-type natriuretic peptide as markers for early detection of acute antipsychotic drugsinduced cardiotoxicity. Cardiovascular toxicology. 11(1):10-7.

Khasawneh FT and Shankar GS (2014): Minimizing cardiovascular adverse effects of atypical antipsychotic drugs in patients with schizophrenia. Cardiology research and practice. 2014.

Leung JY, Barr AM, Procyshyn RM et al., (2012): Cardiovascular side-effects of antipsychotic drugs: the role of the autonomic nervous system. Pharmacology therapeutics.135(2):113-22.

Levine M, Brooks DE, Franken A et al., (2012): Delayed-onset seizure and cardiac arrest after amitriptyline overdose, treated with intravenous lipid emulsion therapy. PediatricsEnglish Edition. 130(2):e432.

Levine M and Ruha AM (2012) :Overdose of atypical antipsychotics. CNS drugs. 26(7):601-11.

Liebelt EL (2008): An update on antidepressant toxicity: an evolution of unique toxicities to master. Clinical Pediatric Emergency Medicine. 9(1):24-34.

Manini AF, Stimmel B, Hoffman RS et al., (2016): Utility of cardiac troponin to predict drug overdose mortality. Cardiovascular toxicology.16(4):355-60.

McGrath JL and Bachmann DJ (2018): Vital Signs measurements. In: Roberts and Hedges' Clinical Procedures in Emergency Medicine E-Book Roberts JR, Hedges JR (eds), $7^{\text {th }}$ ed., Elsevier Health Sciences, pp.1-24.

Mishra D and Kumar P (2018): Electrocardiographic changes of antidepressant medication in depressive episode. Int J Adv Med. 5(3):505509.

Mueller C, Breidthardt T, Laule-Kilian K et al., (2007): The integration of BNP and NT-proBNP into clinical medicine. Swiss medical weekly. 137(1-2):4-12.

Naumann D, Rusius V, Margiotta C, et al., (2013): Factors predicting trastuzumab-related cardiotoxicity in a real-world population of women with HER2+ breast cancer. Anticancer research. 33(4):1717-20.

North BJ, Sinclair DA. The intersection between aging and cardiovascular disease. Circulation research. 2012 Apr 13;110(8):1097-108.

Perez EA, Suman VJ, Davidson NE et al., (2008): Cardiac safety analysis of doxorubicin and cyclophosphamide followed by paclitaxel with or without trastuzumab in the North Central Cancer Treatment Group N9831 adjuvant breast cancer trial. Journal of clinical oncology: official journal of the American Society of Clinical Oncology, 26(8), p.1231.

Persson HE, Sjöberg GK, Haines JA, et al., (1998): Poisoning severity score. Grading of acute poisoning. Journal of Toxicology: Clinical Toxicology. 36(3):205-13.

Pierog JE, Kane KE, Kane BG, et al., (2009): Tricyclic antidepressant toxicity treated with massive sodium bicarbonate. The American journal of emergency medicine. 27(9):1168-e3.

Pointon A and Edmunds N (2019): Soluble biomarkers of drug induced cardiotoxicity. In: Handbook of Biomarkers and Precision Medicine, Carini C, Fidock M and van Gool A (eds), $1^{\text {st }}$ ed., CRC press, NY, p 100-107.

Quin P (2005):Suicide risk in relation to level of urbanicity - a population-based linkage study. International Journal of Epidemiology.34(4): 846-852.

Rabkin SW (2015): Impact of age and gender on QT prolongation in patients receiving psychotropics. The Canadian Journal of Psychiatry. 60(5):206-14

Ruha AM and Levine M (2014): Central nervous system toxicity. Emergency medicine clinics of North America. 32(1):205-21.

Sabah KM, Chowdhury AW, Islam MS et al., (2017): Amitriptyline-induced ventricular tachycardia: a case report. BMC research notes. 10(1):286.

Saleh AA, El-Galad GM, El-Masry MK et al., (2013): Morbidity and Mortality Predictors in Patients with Acute Tricyclic Antidepressant Toxicity. Ain Shams Journal of Forensic Medicine and Clinical Toxicology. 20:1-9.

Schwarz ES (2017) Should we be using Poisoning severity Score? J Med Toxicol. 13(2):135145.

Sorodoc V, Sorodoc L, Ungureanu D et al., (2013): Cardiac troponin $\mathrm{T}$ and NT-proBNP as biomarkers of early myocardial damage in amitriptyline-induced cardiovascular toxicity in rats. International journal of toxicology. 32(5):351-7.

Tan LL and Lyon AR (2018): Role of Biomarkers in Prediction of Cardiotoxicity During Cancer Treatment. Current treatment options in cardiovascular medicine. 20(7):55.

Tan-Chiu E, Yothers G, Romond E et al., (2005): Assessment of cardiac dysfunction in a randomized trial comparing doxorubicin and cyclophosphamide followed by paclitaxel, with or without trastuzumab as adjuvant therapy in node-positive, human epidermal growth factor receptor 2-overexpressing breast cancer: NSABP B-31. Journal of Clinical Oncology. 23(31), pp.7811-7819.

Tarek G, Habib B, Kais G et al., (2016): Tricyclic Antidepressant Intoxication; Several Complications after an Acute Poisoning by Amitriptyline and Clomipramine. J Clin Toxicol. 6(327):2161-0495.

Thanacoody HR and Thomas SH (2005): Tricyclic antidepressant poisoning. Toxicological reviews. 24(3):205-14.

Wallace KB, Hausner E, Herman E, et al., (2004): Serum troponins as biomarkers of drug- 
induced cardiac toxicity. Toxicologic pathology. 32(1):106-21.

Wang YD, Chen SX and Ren LQ (2016): Serum Btype natriuretic peptide levels as a marker for anthracycline-induced cardiotoxicity. Oncol Lett. 11(5):3483-3492.

Waring WS (2012): Clinical use of antidepressant therapy and associated cardiovascular risk. Drug, healthcare and patient safety. 4:93.
Zaaqoq A, Gamaluddin H, El Taftazani E et al., (2012): Poisoning Severity Score as a predictor of cardiotoxicity induced by anticholinesterase pesticides, digoxin and Beta blockers AJFM,19: 53-66.

Zoltani CK (2014): Cardiovascular toxicity markers. In Biomarkers in toxicology. Gupta RC (ed.), $1^{\text {st }}$ ed., Academic Press, Ch 11, p199-215.

\section{الملخص العربى}

\section{البيبتيد الملدر للصوديوم من النوع ب وتروبونين - آى كعلامات بيولوجية محتملة للتنبؤ بالسمية القلبية الناجمة عن الجرعة المفرطة من مضادات الاكتئاب ثلاثية الحلقات ومضادات الذهان}

\section{آية صبري محمد و هدى محمد صلاح الدين و منال السيد عبد السلام}

الجرعة المفرطة من مضادات الاكتئاب ثلاثية الحلقات والأدوية المضادة للذهان يمكن أن تؤدي إلى مضاعفات قلبية سمية يمكن أن تمدد الحياة. في

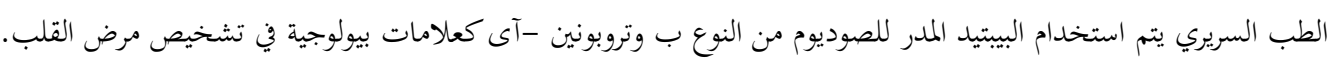

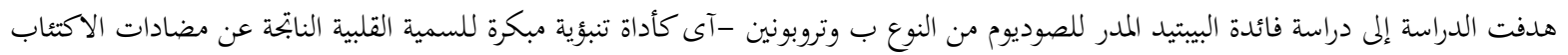

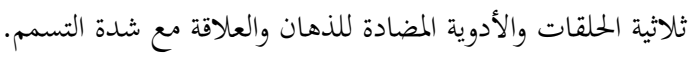

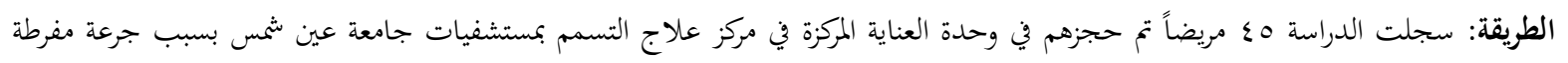

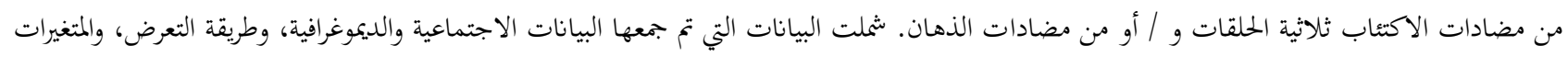

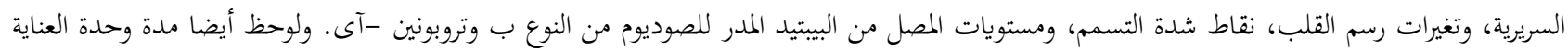
المركزة والإقامة في المستشفى، والنتيجة. النتائج: على عكس مستوى تروبونين -آى، كان مستوى البيبتيد المدر للصوديوم من النوع ب أعلى بكثير في بمموعة السمية القلبية. ارتبط كلل من

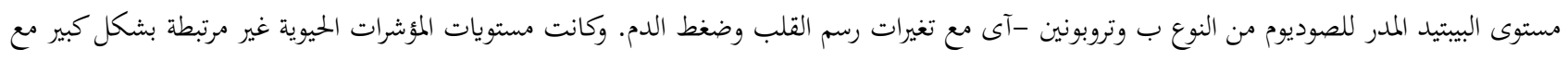
أي من نقاط شدة التسمم وإممالي الإقامة في المستشفى وإقامة وحدة العناية المركزة. كان نقاط شدة التسمم ذات حساسية ودقة منخفضتين للتنبؤ بالسمية

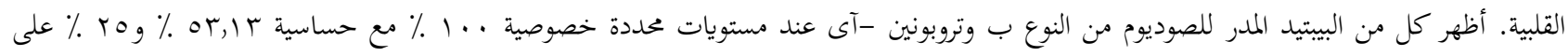
التوالي

الحلاصة: بتحاوز البيتيد المدر للصوديوم من النوع ب وتروبونين -آى كأداة مفيدة لتشخيص السمية القلبية بسبب الجرعة المفرطة من مضادات

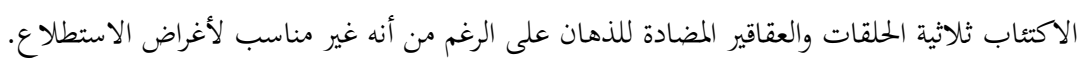

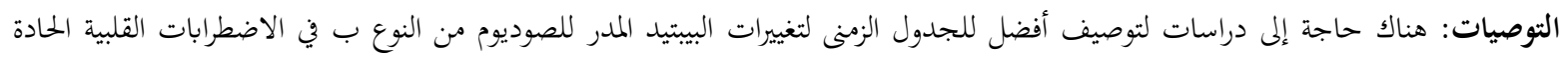

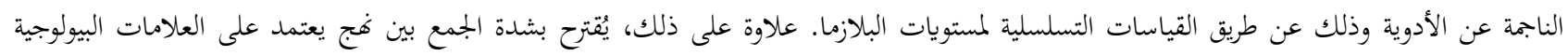

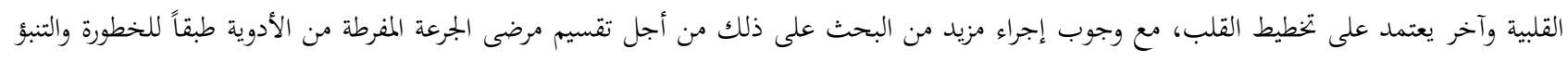

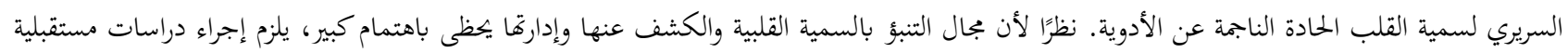

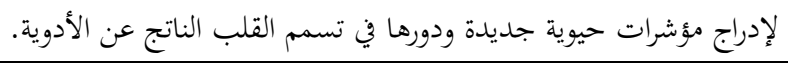

